\title{
Addition of sildenafil in patients with pulmonary arterial hypertension with inadequate response to bosentan monotherapy
}

\author{
Nancy R Porhownik MD, Hassan Al-Sharif MD, Zoheir Bshouty MD PhD FRCPC
}

\begin{abstract}
NR Porhownik, H Al-Sharif, Z Bshouty. Addition of sildenafil in patients with pulmonary arterial hypertension with inadequate response to bosentan monotherapy. Can Respir J $2008 ; 15(8): 427-430$.
\end{abstract}

BACKGROUND: Pulmonary arterial hypertension (PAH) remains a progressive disease despite improvement when using one of three medication classes: prostanoids, endothelin receptor antagonists or phosphodiesterase-5 inhibitors. Combination therapy has been proposed for patients with unsatisfactory response to monotherapy.

OBJECTIVES: To examine the effect of adding sildenafil to bosentan on 6 min walk distance (6MWD) and New York Heart Association (NYHA) classification in patients with PAH who achieved inadequate improvement with bosentan monotherapy.

METHODS: Patients with idiopathic PAH or connective tissue disease-associated PAH, and who had either self-reported inadequate improvement in exercise tolerance or a decline in 6MWD after initial improvement, were included in the study $(n=10)$. Data on 6MWD and NYHA class at baseline (before initiation of bosentan), three and six months after baseline, second baseline (before initiation of combination therapy with sildenafil), and three and six months after second baseline were analyzed for any changes.

RESULTS: Mean time from initiation of bosentan monotherapy to initiation of combination therapy was 558 days (range 150 to 900 days). Six months after initiation of bosentan, 6MWD increased by $57.2 \mathrm{~m}$ above the baseline of $314.4 \mathrm{~m}$. Six months after combination therapy, 6MWD was $62.80 \mathrm{~m}$ higher than the baseline before initiation of combination therapy of $339 \mathrm{~m}(\mathrm{P}<0.02)$. The overall increase in 6MWD six months after combination therapy was higher than the first baseline by $87.4 \mathrm{~m}$ (P not significant). NYHA functional class did not improve with combination therapy in all patients. DISCUSSION: Initiating combination therapy in patients who achieve an inadequate improvement in exercise tolerance with monotherapy may result in further improvement in exercise tolerance.

Key Words: Bosentan; Combination therapy; Pulmonary arterial hypertension; Sildenafil

Dulmonary arterial hypertension (PAH) is a disease with multiple etiologies and complex pathophysiology. Increasing understanding of the underlying processes has allowed the development of targeted therapies. In recent years, three classes of medications with different modes of action have shown promise in the treatment of PAH: prostanoids, endothelin receptor antagonists and phosphodiesterase-5 inhibitors. Although stabilization and long-term improvement has been achieved with monotherapy, PAH remains a progressive disease and deterioration eventually occurs in almost all patients.

\section{L'ajout de sildénafil chez des patients atteints d'hypertension artérielle pulmonaire ne répondant pas de manière satisfaisante à la monothérapie au bosentan}

HISTORIQUE : L'hypertension artérielle pulmonaire (HAP) demeure
une maladie évolutive malgré l'amélioration apportée par l'usage de l'une
des trois catégories de médicaments suivantes : prostanoïdes, antagonistes
des récepteurs de l'endothéline ou inhibiteurs de la phosphodiestérase-5.
On a proposé une polythérapie pour les patients qui ne répondent pas à la
monothérapie de manière satisfaisante.
OBJECTIFS : Examiner les effets de l'ajout de sildénafil au bosentan sur
une distance de marche de 6 minutes (DM6M) et sur la classification de la
New York Heart Association (NYHA) chez les patients atteints d'HAP pour
qui la monothérapie au bosentan n'apportait pas d'améliorations
satisfaisantes. MÉTHODOLOGIE : Des patients atteints d'HAP idiopathique ou d'HAP associée à une maladie des tissus conjonctifs, qui déclaraient euxmêmes une amélioration insuffisante de la tolérance à l'exercice ou une diminution de la DM6M après une amélioration initiale ont participé à l'étude $(\mathrm{n}=10)$. Les auteurs ont analysé les données sur la DM6M et la classe du NYHA en début d'étude (avant le traitement au bosentan), trois mois et six mois après le début de l'étude, à la deuxième date de départ (avant le traitement au sildénafil) ainsi que trois et six mois plus tard afin d'établir s'ils constataient des changements.

RÉSULTATS : Le temps moyen entre le début de la monothérapie au bosentan et le début de la polythérapie était de 558 jours (plage de 150 à 900 jours). Six mois après le début du traitement au bosentan, la DM6M avait augmenté de 57,2 m par rapport à la distance de départ de 314,4 m. Six mois après le début de la polythérapie, la DM6M avait augmenté de $62,80 \mathrm{~m}$ par rapport aux $339 \mathrm{~m}$ au début de la polythérapie $(\mathrm{P}<0,02)$. L'augmentation globale de la DM6M six mois après la polythérapie était supérieure de 87,4 $\mathrm{m}$ à la première mesure de départ (P non significatif). Chez tous les patients, la classe fonctionnelle de la NYHA ne s'améliorait pas avec la polythérapie.

EXPOSÉ : L'adoption de la polythérapie peut favoriser une meilleure tolérance à l'exercice chez les patients dont la tolérance à l'exercice n'atteint pas un taux satisfaisant avec la monothérapie.

There are several rationales for combination therapy in $\mathrm{PAH}$, including targeting multiple disease pathways, enabling synergistic drug activity, overcoming treatment-limiting toxicity of certain monotherapies, allowing for potential dose reductions, and improving clinical outcomes such as time to transplant and progression of symptoms (1). Studies of pharmacokinetic interactions between bosentan and sildenafil demonstrate a mutual pharmacokinetic interaction among the drugs that may influence their bioavailability; however, clinical implications of these interactions remain undetermined (2). 
TABLE 1

\section{Patient demographics}

\begin{tabular}{lcccc}
\hline $\begin{array}{l}\text { Patient } \\
\text { number }\end{array}$ & $\begin{array}{c}\text { Age, } \\
\text { years }\end{array}$ & Sex & Diagnosis & $\begin{array}{c}\text { Days from initiation of } \\
\text { monotherapy to } \\
\text { combination therapy }\end{array}$ \\
\hline 1 & 72 & $\mathrm{~F}$ & IPAH & 420 \\
2 & 58 & $\mathrm{M}$ & IPAH & 390 \\
3 & 34 & $\mathrm{~F}$ & IPAH & 150 \\
4 & 62 & $\mathrm{~F}$ & IPAH & 450 \\
5 & 51 & $\mathrm{~F}$ & IPAH & 720 \\
6 & 42 & $\mathrm{~F}$ & IPAH & 570 \\
7 & 27 & $\mathrm{~F}$ & CTD-PAH & 480 \\
8 & 24 & $\mathrm{M}$ & IPAH & 630 \\
9 & 72 & $\mathrm{~F}$ & CTD-PAH & 900 \\
10 & 55 & $\mathrm{~F}$ & IPAH & 870 \\
Mean & 49.7 & - & & 558 \\
(range) & $(24-72)$ & - & - & $(150-900)$ \\
\hline
\end{tabular}

CTD-PAH Connective tissue disease-associated pulmonary arterial hypertension; F Female; IPAH Idiopathic pulmonary arterial hypertension; M Male

Although evidence of benefit of combination therapies from well-designed, randomized, controlled trials is not available, many PAH centres are using combinations as part of a goaloriented treatment approach. Survival rates of patients with $\mathrm{PAH}$ of various etiologies treated with combination therapy (bosentan, sildenafil, iloprost) according to a goal-directed treatment algorithm and compared with a historical control, improved to $93.0 \%, 83.1 \%$ and $79.9 \%$ after one, two and three years, respectively (3). Survival rates of patients with untreated PAH have been estimated to be $68 \%, 48 \%$ and $34 \%$ after one, three and five years, respectively (4). Survival data are available on patients initiated on bosentan monotherapy; however, medication was modified during the observation period if monotherapy failed. Survival data of patients on bosentan monotherapy alone are not available.

In the present study, we prospectively examined the effect of adding sildenafil, a phosphodiesterase- 5 inhibitor, to bosentan, a nonselective endothelin receptor antagonist, on $6 \mathrm{~min}$ walk distance (6MWD) and clinical class (New York Heart Association [NYHA]) in patients with PAH who were initiated on monotherapy with bosentan and either did not achieve an adequate improvement in exercise tolerance over time or had a decline in exercise tolerance following an initial improvement. The 6MWD, a measure of exercise capacity, has been shown to be a strong predictor of mortality at baseline and after initiation of therapy (5). Combination therapy with bosentan and sildenafil is of keen interest to clinicians and patients because of the ease of drug administration (both oral agents), effect on different pathophysiological pathways, and well-studied safety and tolerability of the drugs.

\section{Study subjects}

\section{METHODS}

Patients with a diagnosis of either idiopathic PAH (IPAH) or connective tissue disease-associated PAH (CTD-PAH) were considered for the present study. A diagnosis of PAH was confirmed in all patients by right heart catheterization. All patients were initiated on bosentan monotherapy with the intention of attempting combination therapy with sildenafil if they did not improve on monotherapy. Patients who reported poor exercise tolerance (ie, inadequate improvement in symptoms) or did not reach published goal-directed therapy targets for 6MWD (greater than $380 \mathrm{~m}$ ) (1) following an initial improvement with bosentan monotherapy were included in the study. A drop in 6MWD of greater than $50 \mathrm{~m}$ was considered clinically significant when assessing individual patients. NYHA classification for dyspnea was recorded, although patients' lack of subjective improvement in symptoms was considered the more relevant clinical response. Patients who improved or stabilized with bosentan monotherapy and those with other causes of $\mathrm{PAH}$ were excluded from the study. Informed consent was obtained from all patients for inclusion in the present study and in the Health Sciences Centre (Winnipeg, Manitoba) PAH database for future observational studies. Institutional approval was granted by the research ethics board. Results of research projects involving these patients are made available to the patients on a regular basis.

\section{Investigations}

Patients were followed prospectively with repeat 6MWD at least every three months. Tests were performed by certified cardiopulmonary technicians according to American Thoracic Society standards (6), with the exception that technicians support the weight of pulse oximeters and oxygen tanks, requiring them to walk behind patients. Clinical status was assessed and recorded by a respiratory nurse clinician with clinical training in PAH during routine patient visits according to the NYHA functional class (7). The nurse clinician was not blinded to the patients' treatments.

\section{Statistical analysis}

Data at baseline 6MWD (before initiation of bosentan), three and six months after baseline, second baseline (before initiation of combination therapy), and three and six months after second baseline were analyzed using repeated measures ANOVA with specific comparisons. This analysis lends statistical power to the study population, in which each patient acts as his or her own control. Change in 6MWD was the primary end point and NYHA functional classification was the secondary end point. $\mathrm{P}<0.05$ was considered to be statistically significant.

\section{RESULTS}

Patient demographics are outlined in Table 1. Ten patients, (eight women and two men) met the inclusion criteria for the study. Eight patients had IPAH and two female patients had CTD-PAH. Mean age of the patients was 49.7 years (range 24 to 72 years). Mean time from initiation of bosentan monotherapy to initiation of combination therapy was 558 days (range 150 to 900 days).

Table 2 describes individual patient and mean 6MWD before and after combination therapy. Mean baseline 6MWD before initiation of bosentan therapy was $314.4 \mathrm{~m} \mathrm{(95 \%} \mathrm{CI} 231.6 \mathrm{~m}$ to $397.2 \mathrm{~m}$ ). Six months after initiation of bosentan, mean 6MWD increased by an average of $57.2 \mathrm{~m}$ (mean 6MWD $371.6 \mathrm{~m}$, 95\% CI $308.5 \mathrm{~m}$ to $434.7 \mathrm{~m}$ ). Mean 6MWD at the second baseline, before initiating combination therapy, was still higher than the first baseline by $24.6 \mathrm{~m}$ (mean 6MWD $339.0 \mathrm{~m}, 95 \% \mathrm{CI}$ $272.6 \mathrm{~m}$ to $405.4 \mathrm{~m}$ ). Six months after combination therapy was initiated, mean 6MWD was $62.8 \mathrm{~m}$ higher than the second baseline $(\mathrm{P}<0.02)$ (mean 6MWD $401.8 \mathrm{~m}, 95 \%$ CI $327.0 \mathrm{~m}$ to $476.6 \mathrm{~m}$ ). The overall increase in 6MWD six months after combination therapy was higher than the first baseline by $87.4 \mathrm{~m}$ (P not significant). Figure 1 illustrates the trend of the mean 
TABLE 2

Six-minute walk distance (meters) before and after combination therapy

\begin{tabular}{lcccccc}
\hline $\begin{array}{l}\text { Patient } \\
\text { number }\end{array}$ & BL1 & 3M & 6M & BL2 & 3M2 & 6M2 \\
\hline 1 & 240 & 215 & 235 & 235 & 265 & 267 \\
2 & 253 & 320 & 420 & 260 & 305 & 255 \\
3 & 300 & 370 & 430 & 440 & 386 & 425 \\
4 & 280 & 205 & 240 & 220 & 245 & 235 \\
5 & 273 & 273 & 495 & 495 & 580 & 600 \\
6 & 498 & 520 & 490 & 460 & 480 & 440 \\
7 & 220 & 300 & 260 & 260 & 360 & 400 \\
8 & 560 & 560 & 400 & 440 & 504 & 546 \\
9 & 120 & 306 & 306 & 320 & 385 & 415 \\
10 & 400 & 480 & 440 & 260 & 425 & 435 \\
Mean & 314.40 & 354.90 & 371.60 & 339.00 & 393.50 & 401.80 \\
\pm SD & 133.53 & 124.98 & 101.77 & 107.21 & 107.04 & 120.60 \\
\pm SE & 42.23 & 39.52 & 32.18 & 33.90 & 33.85 & 38.14 \\
\hline
\end{tabular}

BL1 Baseline 1 (before bosentan initiation); BL2 Baseline 2 (before initiation of bosentan plus sildenafil therapy); $3 M$ Three months postinitiation of bosentan treatment; 3M2 Three months postinitiation of bosentan plus sildenafil treatment; 6M Six months postinitiation of bosentan treatment; 6M2 Six months postinitiation of bosentan plus sildenafil treatment

6MWD, including the SD. There was a trend toward improvement in the mean 6MWD when comparing the starting point of the study to both three months and six months of treatment with combination therapy; however; this improvement was not statistically significant.

NYHA classifications are described in Table 3. Seven patients had class III symptoms before initiation of bosentan monotherapy (baseline 1), and three patients had class II symptoms. From first baseline to second baseline (before initiation of bosentan and sildenafil combination therapy), six of 10 patients had no change in their functional classification, three patients had improved by one classification and one patient had deteriorated by one classification. From initiation of combination therapy to six months later, seven of 10 patients had no change in their NYHA classification and three patients improved by one class.

None of the patients required medication adjustments for increased liver enzymes.

\section{DISCUSSION}

Initiation of combination therapy with bosentan and sildenafil in patients who do not achieve an adequate improvement in subjective exercise tolerance or 6MWD with bosentan monotherapy, even after approximately 1.5 years of treatment, may result in further improvement in exercise tolerance. Hoeper et al (8) reported similar results with sildenafil and bosentan in nine of 58 patients with PAH treated with bosentan (with or without a prostanoid). Sildenafil was added for these patients who failed to meet the goals of therapy (6MWD of greater than $380 \mathrm{~m}$ and peak $\mathrm{O}_{2}$ uptake during cardiopulmonary exercise testing of greater than $10.4 \mathrm{~mL} / \mathrm{min} / \mathrm{kg}$ ). After an initial improvement and subsequent decline in 6MWD on bosentan (with or without prostanoid) therapy, 6MWD increased and remained stable with the addition of sildenafil for the median follow-up of nine months.

The patients in our study can be divided into three major groups based on their 6MWD response to bosentan monotherapy:

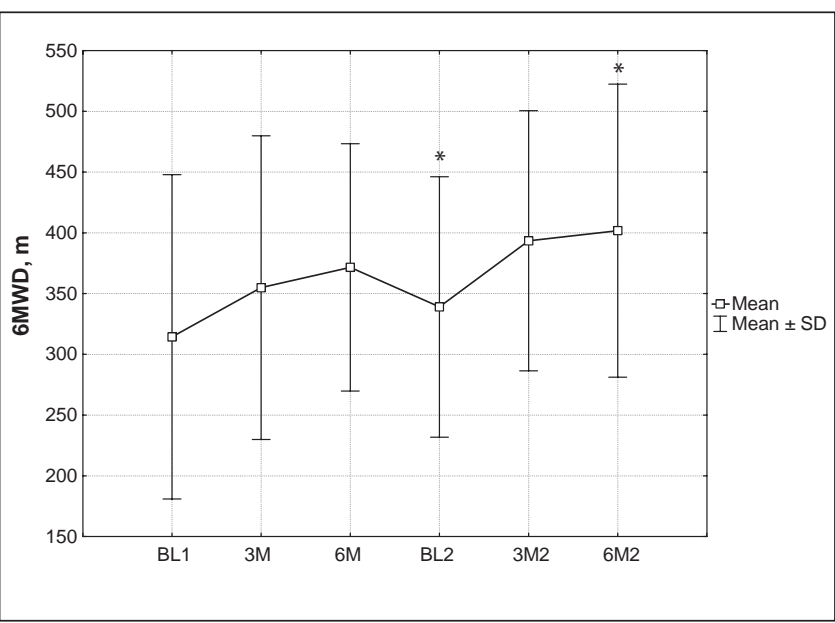

Figure 1) Mean 6 min walk distance (6MWD) before and after combination therapy. $* P<0.02$. BL1 Baseline 1 (before bosentan initiation); BL2 Baseline 2 (before initiation of bosentan plus sildenafil therapy); $3 \mathrm{M}$ Three months postinitiation of bosentan treatment; 3M2 Three months postinitiation of bosentan plus sildenafil treatment; $6 \mathrm{M}$ Six months postinitiation of bosentan treatment; 6M2 Six months postinitiation of bosentan plus sildenafil treatment

\section{TABLE 3}

New York Heart Association functional classification before and after combination therapy

\begin{tabular}{|c|c|c|c|c|c|c|}
\hline $\begin{array}{l}\text { Patient } \\
\text { number }\end{array}$ & BL1 & $3 \mathrm{M}$ & $6 \mathrm{M}$ & BL2 & $3 \mathrm{M} 2$ & $6 \mathrm{M} 2$ \\
\hline 1 & III & III & III & III & III & III \\
\hline 2 & III & III & II & III & III & III \\
\hline 3 & III & II & II & II & II & II \\
\hline 4 & III & III & III & III & III & III \\
\hline 5 & III & III & II & II & I & I \\
\hline 6 & II & I & II & II & II & II \\
\hline 7 & III & III & III & III & II & II \\
\hline 8 & II & II & II & II & II & II \\
\hline 9 & III & II & II & II & II & II \\
\hline 10 & II & 1 & II & III & II & II \\
\hline Mean & 2.70 & 2.30 & 2.30 & 2.50 & 2.20 & 2.20 \\
\hline$\pm \mathrm{SD}$ & 0.48 & 0.82 & 0.48 & 0.53 & 0.63 & 0.63 \\
\hline$\pm \mathrm{SE}$ & 0.15 & 0.26 & 0.15 & 0.17 & 0.20 & 0.20 \\
\hline
\end{tabular}

BL1 Baseline 1 (before bosentan initiation); BL2 Baseline 2 (before initiation of bosentan plus sildenafil therapy); $3 M$ Three months postinitiation of bosentan treatment; 3M2 Three months postinitiation of bosentan plus sildenafil treatment; 6M Six months postinitiation of bosentan treatment; 6M2 Six months postinitiation of bosentan plus sildenafil treatment

group 1, subjects that did not improve (patients 1, 4 and 8); group 2, subjects that improved initially and subsequently deteriorated (patients 2, 6 and 10); and group 3, subjects that improved and stabilized but not to a satisfactory level (patients 3, 5, 7 and 9). For group 1, two of the three patients (numbers 1 and 8 ) had improved with the addition of sildenafil, while the third patient (number 4) remained stable but did not improve. In group 2, there was no consistency of the response to combination therapy. In group 3, the response was similar to that in group 1. Three of the patients (numbers 5, 7 and 9) improved with combination therapy, while the fourth patient (number 3) declined initially with the addition of sildenafil. 
Thus, the two groups that tended to improve 6MWD with combination therapy were patients who did not improve their 6MWD on bosentan alone, and those who improved and stabilized their 6MWD on bosentan, but were dissatisfied with their exercise tolerance.

Mathai et al (9) studied the addition of sildenafil to bosentan in patients with both IPAH and PAH associated with scleroderma (PAH-SSD) who deteriorated symptomatically, by one NYHA functional class, or by more than $30 \mathrm{~m}$ on 6MWD. Patients with IPAH had improved functional capacity and 6MWD, whereas patients with PAH-SSD did not. In contrast to our own results, the majority of patients who improved with combination therapy (both IPAH and PAHSSD) in Mathai's study had initially improved with bosentan monotherapy. Although it is difficult to make firm conclusions about differing responses of patients with IPAH versus patients with CTD-PAH (only two enrolled in the present study), it is interesting to note that, unlike in Mathai's study, the two CTD-PAH patients (number 7 and number 9) both improved with combination therapy. Patient 7 improved in both 6MWD and NYHA classification with combination therapy, and patient 9 maintained the same NYHA class but

\section{REFERENCES}

1. Hoeper MM, Markevych I, Spiekerkoetter E, Welte T, Niedermeyer J. Goal-oriented treatment and combination therapy for pulmonary arterial hypertension. Eur Respir J 2005;26:858-63.

2. Burgess G, Hoogkamer H, Collings L, Dingemanse J. Mutual pharmacokinetic interactions between steady-state bosentan and sildenafil. Eur J Clin Pharmacol 2008;64:43-50.

3. Sitbon $\mathrm{O}$, Humbert $\mathrm{M}$, Nunes $\mathrm{H}$, et al. Long-term intravenous epoprostenol infusion in primary pulmonary hypertension: Prognostic factors and survival. J Am Coll Cardiol 2002;347:322-9.

4. D'Alonzo GE, Barst RJ, Ayres SM, et al. Survival in patients with primary pulmonary hypertension. Ann Intern Med 1991;115:343-9. had further improvements in 6MWD with combination therapy.

The results of the present study support the use of combination therapy with bosentan and sildenafil in patients who have either a decline in 6MWD or inadequate improvement exercise tolerance on bosentan monotherapy. The mean improvement in 6MWD was statistically significant following the introduction of the second drug. These patients may benefit from a short course of combination therapy with sildenafil (ie, three to six months). If further decline or no improvement is apparent with the additional medication, alternative treatments should be sought.

A major limitation of the present prospective observational study is the small size, and as such, responses of our subgroups are only suggestive of true responses. Other limitations include the lack of randomization to a blinded, bosentan plus placebocontrolled arm, and the lack of blinding of the staff performing the 6MWD and assessing NYHA classification. Because much of the available data regarding combination treatments for IPAH are equally limited, larger, randomized controlled trials are required to further address the benefits of combination therapy on improved quality of life and survival in patients with PAH.

5. O'Callaghan D, Gaine SP. Combination therapy and new types of agents for pulmonary arterial hypertension. Clin Chest Med 2007;28:169-85.

6. ATS statement: Guidelines for the six-minute walk test. Am J Respir Crit Care Med 2002;166:111-7.

7. The Criteria Committee of the New York Heart Association. Nomenclature and Criteria for Diagnosis of Diseases of the Heart and Great Vessels, 9th edn. Boston: Little, Brown, \& Co, 1994:253-6.

8. Hoeper MM, Faulenbach C, Golpon H, et al. Combination therapy with bosentan and sildenafil in idiopathic pulmonary arterial hypertension. Eur Respir J 2004:24:1007-10.

9. Mathai SC, Girgis RE, Fisher MR, et al. Addition of sildenafil to bosentan monotherapy in pulmonary arterial hypertension. Eur Respir J 2007;29:469-75. 


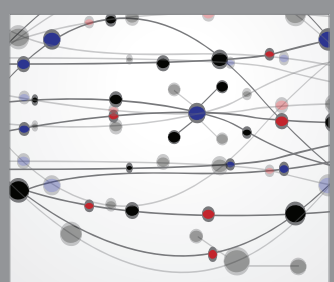

The Scientific World Journal
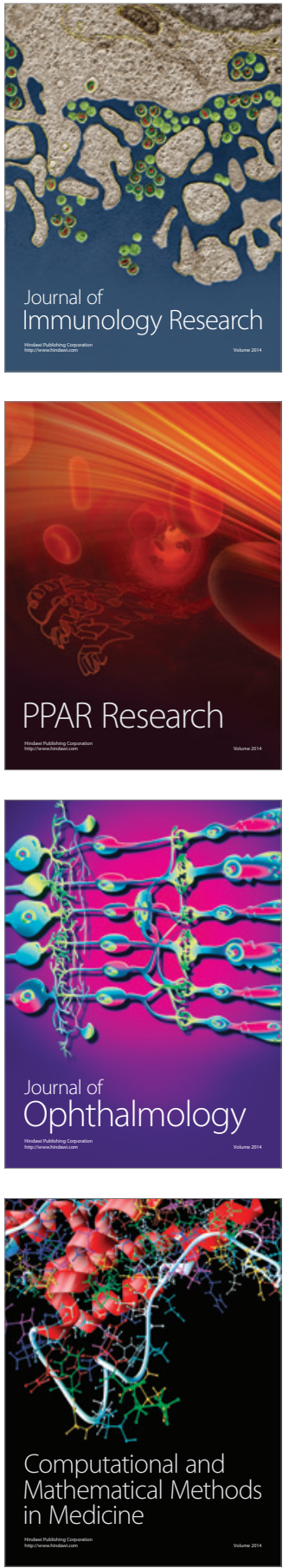

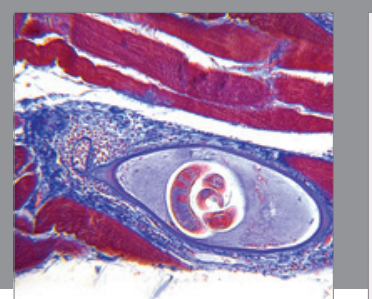

Gastroenterology Research and Practice

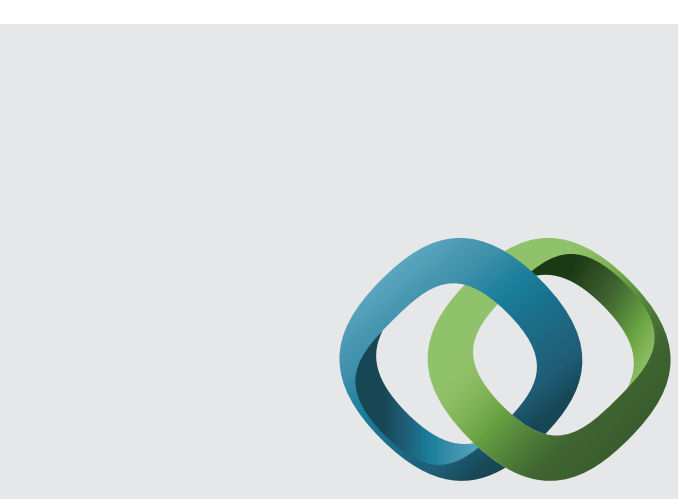

\section{Hindawi}

Submit your manuscripts at

http://www.hindawi.com
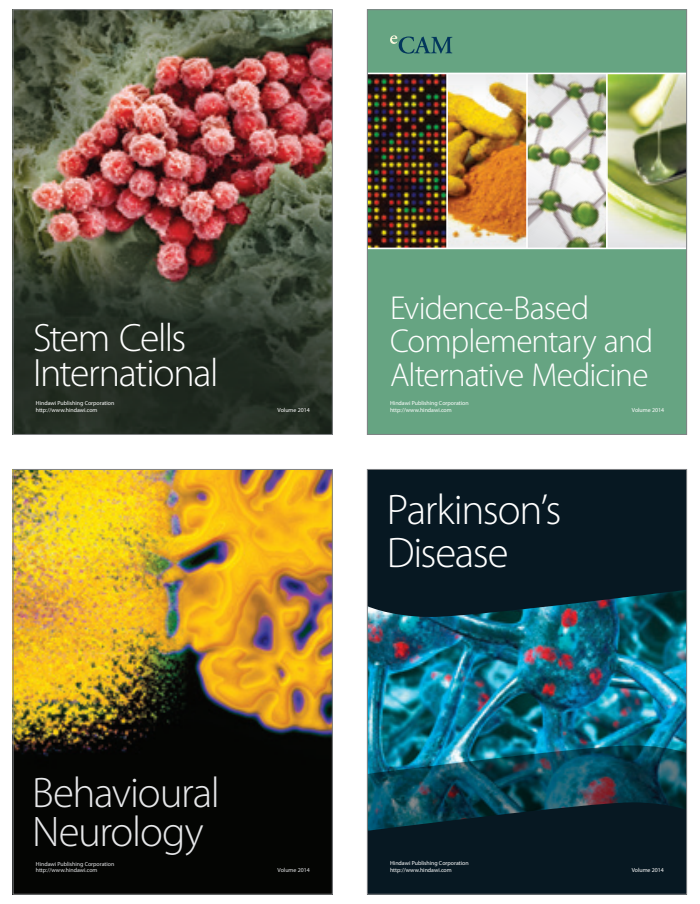
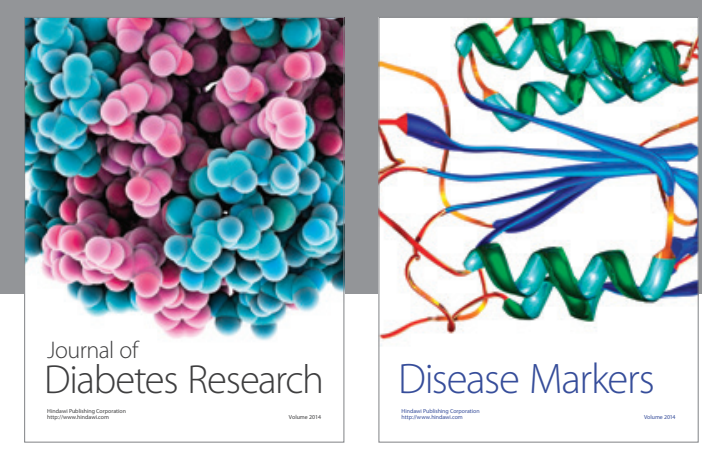

Disease Markers
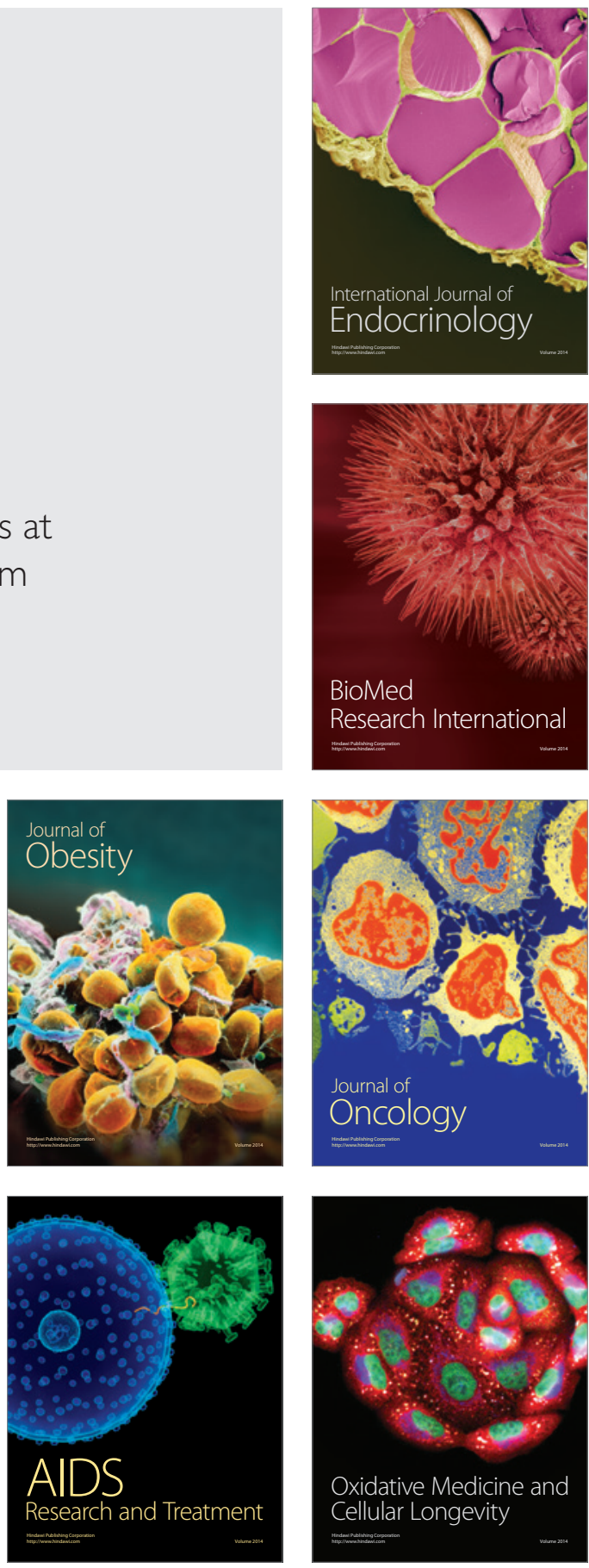